\title{
The Potential Effect of Gynura Procumbens Aqueous Extract as Anti-Hyperglycaemia, Pro-Fertility and Libido Agent Towards Diabetes-Induced Male Rats
}

\author{
Khaidatul Akmar, Mahanem Mat Noor \\ Faculty of Science \& Technology, Universiti Kebangsaan Malaysia, Bangi, Malaysia
}

\begin{abstract}
Diabetes mellitus is a metabolic disorder that often affected fertility health, specifically in men. Gynura procumbens (G. procumbens) has been used as traditional medicine due to its ability in treating various types of illness. Hence, this study was carried out to determine the potential beneficial effect of $G$. procumbens as anti-hyperglycaemia, pro-fertility and libido agent towards diabetesinduced male rats. A total of 42 male Sprague Dawley rats were randomly assigned into six groups; normal, negative, and positive control, and three treated groups of different dosages of G. procumbens aqueous extract (GPAE); $150 \mathrm{mg} / \mathrm{kg}, 300 \mathrm{mg} / \mathrm{kg} \mathrm{and} 450 \mathrm{mg} / \mathrm{kg}$. Each group was given treatment via oral gavage for seven consecutive days. The rats were sacrificed on day eighth for further analysis. The fasting blood glucose (FBG) level in all GPAE treated group showed significant decrease, and $450 \mathrm{mg} / \mathrm{kg}$ treated group showed significant reduction to a normal blood glucose level compared to all groups. There were significant increases in the sperm quality of GPAE treated groups after seven days of treatment compared to the negative and positive control group, specifically in $450 \mathrm{mg} / \mathrm{kg}$ treated group. Testis histology showed that GPAE treated groups produced a significant result whereby the seminiferous tubules were seen packed with sperm and successive stage of spermatogenesis were shown compared to control groups. Hormone analysis suggested that the luteneizing hormone ( $\mathrm{LH})$, follicle stimulating hormone (FSH) and testosterone hormone of the treated groups were elevated after seven days of treatment compared to the negative and positive control groups. Libido analysis of seven days treatment showed that GPAE treated groups, significantly improved in $450 \mathrm{mg} / \mathrm{kg}$ dose compared to other groups, with the highest number of mounting frequency and shortest mounting latency. Fertility test revealed a significant increase in number of implantation sites produced in GPAE treated groups compared to positive and negative control groups. In conclusion, GPAE exhibited a potential beneficial effect as an anti-diabetic and also as fertility agent in diabetic-induced male rats.
\end{abstract}

Keywords: Gynura procumbens, diabetes mellitus, hyperglycaemia, male fertility, libido.

\section{INTRODUCTION}

Diabetes mellitus is a metabolic disorder that caused by insufficient of insulin or no insulin secretion, which resulted a condition called hyperglycaemia. Prolonged hyperglycaemia often associated with male fertility health, specifically significant reduction in sperm quality, damaged structure and function of testes, as well as decrease of libido (La Vignera, 2012; Hakim et al., 2016; Kamaruzaman \& Noor, 2017). Established drug for hyperglycaemia such as metformin was known to reduce fasting blood glucose level of diabetes patients, however, could not improve diabetes mellitus complication, male fertility health (Alvez, 2013).

Medicinal plant or herbs have been long used in traditional medicine in treating disease such as inflammation, hypertension and diabetes mellitus (Jantan, 2004). To date, due to its potential in treating diseases traditionally, herbs or these medicinal plants have been explored as an alternative in treating ailments conventionally. Herbs like Tongkat ali, Kacip Fatimah, Dukung anak have been widely explored for their potential therapeutic effects (Jantan, 2004). Interestingly, Gynura procumbens, a medicinal plant showed beneficial therapeutic effect as anti-hyperglycaemia as well as fertility enhancer in male reproductive health (Rosidah et al., 2008; Zurina et al., 2010).

Gynura procumbens (G. procumbens) is a medicinal plant that is also known as Sambung Nyawa in Malay. This shrub can be found in Southeast Asia, namely in Indonesia, Thailand and Cambodia (Lemmens \& Bunyapraphatsara, 2003). G. procumbens is reported to be able to treat fever, rashes and also hypertension (Tan et al., 2016). Previous studies reported that $G$. procumbens contain flavonoids and antioxidants which contribute to these potential therapeutic effects (Rosidah et al., 2008; Algariri et al., 2014).

$G$. procumbens was also reported to have antihyperglycaemia effect as well as male fertility effect, however, lack of data was shown for the duration for this herb start to give the effects. Thus, the aim of this study is to assess the anti-hyperglycaemia and fertility effects of $G$. procumbens aqueous extract on male diabetes rats within seven days of treatment.

\section{MATERIAL AND METHODS}

\section{Preparation of G. procumbens}

For this study, only the leaves part of this herbal plant, G. procumbens were used. The herbal were collected in 
the Glass house, UKM and processed until it produced the aqueous extract of $G$. procumbens in freeze-dried form. The sample later kept in $4^{\circ} \mathrm{C}$ to keep its freshness until used.

\section{Animal Husbandry}

A total of 42 male Sprague Dawley rats were used in this study. All of the rats were proven fertile and provided by the Animal House, UKM. All animals were acclimatized for seven days and the food and drink intake were given ad libitum.

For this study, all rats were divided randomly into six different groups. Three of which were categorized as treatment group; $150 \mathrm{mg} / \mathrm{kg} \mathrm{GP}, 300 \mathrm{mg} / \mathrm{kg}$ GP and 450 $\mathrm{mg} / \mathrm{kg}$ GP. Another three groups were categorized as control group; Normal $(\mathrm{N})$, positive $(\mathrm{M})$ and negative control (DM). All groups except normal (N) group were induced with streptozotocin (STZ) at the dose of 50 $\mathrm{mg} / \mathrm{kg}$. Positive control was treated with metformin (500 $\mathrm{mg} / \mathrm{kg}$ ) while negative control will remain untreated throughout the experiment. Treatment was given via oral gavage for seven consecutive days. On the $8^{\text {th }}$ day, all rats will be sacrificed for further fertility study. This study was approved by the Animal Ethics Committee of Faculty of Medicine, Universiti Kebangsaan Malaysia (FST/2013/MAHANEM/31-JAN./492-FEB.-2013-FEB.2015).

\section{Induction of STZ}

Streptozotocin (STZ) was prepared in citrate buffer, $\mathrm{pH}$ 4.5 at the dose of $50 \mathrm{mg} / \mathrm{kg}$ per rats. Rats were induced with single intravenous injection of Streptozotocin (STZ) at the root of the rats' tail after fasting overnight. Blood glucose level that elevates $13 \mathrm{mmol} / \mathrm{L}$ will be considered as diabetic.

\section{Fasting blood glucose level analysis}

After treatment of seven days, FBG level was measured using glucometer Accucheck perfoma. Blood was collected from the tip of the tail using glucose strip and FBG level was taken.

\section{Sperm quality analysis}

The rats were sacrificed and the cauda epididymis was removed to obtain the sperm samples. The caudal epididymis was minced and suspended in the BiggersWhitten-Whittingham medium (Biggers et al., 1971). The samples were then incubated in $5 \% \mathrm{CO}_{2}$ incubator for 30 minutes at $37^{\circ} \mathrm{C}$ to allow the sperm to swim up. The sperm sample quality was assessed based on the parameters: sperm count, motility, and viability. The sperm samples were assessed according to the WHO laboratory manual (2010).

\section{Spermatogenesis study}

Spermatogenesis study was performed by both quantitative and qualitative analysis. Testes were removed and fixed in a Bouins Solution for overnight. The testes later were dehydrated using series of alcohols and finally embedded in paraffin. Testes samples were sectioned at $5 \mu \mathrm{m}$ in thickness and stained using Mallory staining. Testicular histology was observed under light microscope. Quantitative analysis was performed by measuring the thickness of germ cell on testicular histology of all groups.

\section{Sexual behaviour study}

Sexual behaviour test was performed to determine the effect of the treatment on rats after seven days of treatment. The test was performed according to the rat sexual protocol proposed by Agmo (1997). Healthy female rats were used in this study and made receptive for sexual activity test. A male rat was placed in the test cage for the first five minutes and then followed by the female rat. The observation period was within 15 minutes. Sexual behaviour was determined by observing the mounting frequency and mounting latency.

\section{Implantation sites}

After seven days of treatment, each male rat was kept in a different cage together with two oestrous female rats. The rats were allowed to mate for seven days. Vaginal smears were performed to determine the gestation day. Pregnant female rats were later separated and kept for 16 days before sacrificed and the number of foetuses in the uterus was recorded (Chauhan \& Agarwal, 2009).

\section{Statistical analysis}

The data were displayed as mean \pm standard error of means (SEM). The statistical analysis performed using the one-way analysis of variance (ANOVA) with the value of $p<0.05$ considered as statistically significant.

\section{RESULTS AND DISCUSSION}

\section{Fasting blood glucose level}

Based on the results, the administration of $G$. procumbens aqueous extract at all three dosages showed significant reduction of FBG level compared to both negative $(25.99 \pm 2.07 \mathrm{mmol} / \mathrm{L})$ and positive control $(18.37 \pm 1.38 \mathrm{mmol} / \mathrm{L})$. All treated group; $150 \mathrm{mg} / \mathrm{kg} \mathrm{GP}$, $300 \mathrm{mg} / \mathrm{kg}$ GP and $450 \mathrm{mg} / \mathrm{kg} \mathrm{GP}$, were not significant compared to normal group $(4.97 \pm 0.63 \mathrm{mmol} / \mathrm{L})$, with FBG level at $(16.99 \pm 3.14 \mathrm{mmol} / \mathrm{L}, 12.94 \pm 2.07 \mathrm{mmol} / \mathrm{L}$ and $7.4 \pm 2.07 \mathrm{mmol} / \mathrm{L})$, respesctively. Thus, this implies that the administration of $G$. procumbens aqueous extract reduced blood glucose level (Figure 1). Treatment of metformin in positive control showed a decrease of FBG level. However, the decrease was not significant compared to normal level FBG. 


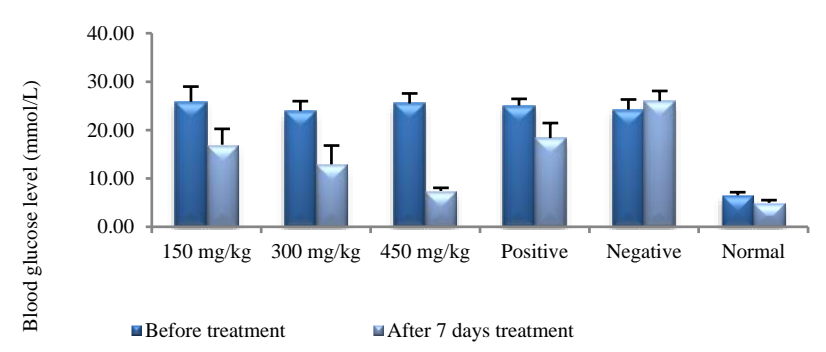

Figure 1.: Histogram showed fasting blood glucose level of each group before and after 7 days of treatment

\section{Sperm quality analysis}

The effect of oral administration of $G$. procumbens aqueous extract for seven consecutive days on the sperm quality of diabetic induced male rats was shown in Table 1. Daily administration of treatment showed that the overall sperm quality was significantly increased in treated groups compared to negative and positive control. Treatment of metformin in positive control however, showed no improvement of sperm quality compared to treatment groups.

Table 1. Table showed the sperm quality of each group after 7 days of treatment

\begin{tabular}{ccccc}
\hline Group & $\begin{array}{c}\text { Sperm Count } \\
\left(\times \mathbf{1 0}^{\mathbf{6}}\right)\end{array}$ & $\begin{array}{c}\text { Sperm } \\
\text { Motility } \\
\text { (Progressive } \\
\text { movement) }\end{array}$ & $\begin{array}{c}\text { Sperm } \\
\text { Viability }\end{array}$ & $\begin{array}{c}\text { Sperm } \\
\text { Morphology }\end{array}$ \\
\hline Normal & $37.27 \pm 0.61$ & $44.80 \pm 3.60$ & $75.30 \pm 2.55$ & $77.80 \pm 1.89$ \\
Negative & $18.07 \pm 3.18$ & $23.40 \pm 5.28$ & $44.31 \pm 6.87$ & $48.30 \pm 2.17$ \\
Positive & $23.43 \pm 2.63$ & $20.38 \pm 6.40$ & $48.10 \pm 9.9$ & $56.92 \pm 6.11$ \\
$150 \mathrm{mg} / \mathrm{kg}$ & $26.79 \pm 2.42$ & $34.69 \pm 2.68$ & $67.54 \pm 3.62$ & $77.16 \pm 2.48$ \\
$300 \mathrm{mg} / \mathrm{kg}$ & $25.75 \pm 3.57$ & $45.40 \pm 4.12$ & $76.21 \pm 4.54$ & $80.97 \pm 1.92$ \\
$450 \mathrm{mg} / \mathrm{kg}$ & $33.63 \pm 1.89$ & $35.50 \pm 6.17$ & $78.72 \pm 7.27$ & $79.89 \pm 1.19$ \\
\hline
\end{tabular}

\section{Spermatogenesis study}

Qualitative analysis of spermatogenesis of all groups was shown in Figure 2. Testes histology of the negative and positive control showed empty lumen with disrupted spermatogenesis. Based on the result, testicular tissue sections in the treated group indicated that the treatment of $G$. procumbens aqueous extract improve testicular impairment with the appearance of Sertoli and Leydig cells. The lumen in each treatment group packed with sperm implies that spermatogenesis was not interrupted.

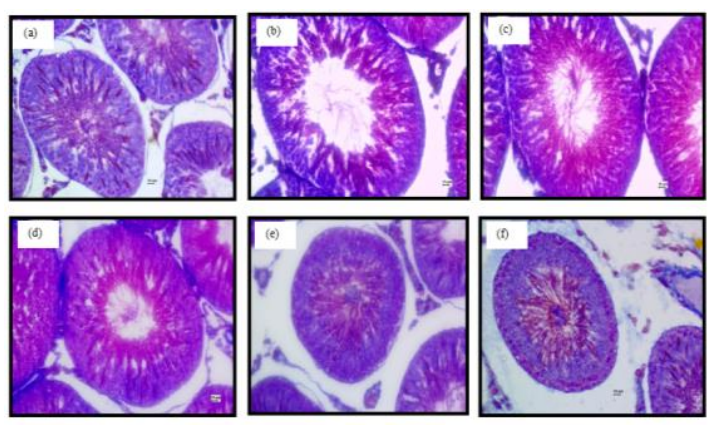

Figure 2. Diagram showed testes histology of each group after 7 days of treatment; (a) Normal, (b) Negative, (c) Positive, (d) $150 \mathrm{mg} / \mathrm{kg}$, (e) 300 $\mathrm{mg} / \mathrm{kg}$, and (f) $450 \mathrm{mg} / \mathrm{kg}$; $400 \mathrm{x}$; Mallory staining.
Androgen hormone (Testosterone, Luteinizing and Follicle-stimulating hormone)

Hormone levels for testosterone, LH, and FSH are shown in Table 2. On the basis of the results, all three hormones decreased in the diabetic rat group compared with the normal group. Furthermore, the use of metformin did not improve the levels of hormones in comparison with the diabetic group. Conversely, all GPAE treatment groups showed increasing trends of testosterone, LH, and FSH hormone levels, specifically at the dosage of $450 \mathrm{mg} / \mathrm{kg}(0.802 \pm 0.014 \mathrm{ng} / \mathrm{mL}, 0.054$ $\pm 0.026 \mathrm{ng} / \mathrm{mL}$, and $0.067 \pm 0.012 \mathrm{ng} / \mathrm{mL}$, respectively) (Table 1).

Table 2. Table showed androgen hormone levels of each group after 7 days of treatment, based on Testosterone, Luteinizing hormone and Follicle stimulating hormone.

\begin{tabular}{llll}
\hline Group & $\begin{array}{l}\text { Testosterone } \\
(\mathbf{n g} / \mathbf{m L})\end{array}$ & $\begin{array}{l}\text { Luteinizing } \\
\text { hormone } \\
(\mathbf{m I U} / \mathbf{m L})\end{array}$ & $\begin{array}{l}\text { Follicle } \\
\text { stimulating } \\
\text { hormone } \\
(\mathbf{m I U} / \mathbf{m L})\end{array}$ \\
\hline Normal & $0.75 \pm 0.008$ & $0.044 \pm 0.003$ & $0.059 \pm 0.007$ \\
Negative & $0.17 \pm 0.016$ & $0.022 \pm 0.016$ & $0.025 \pm 0.014$ \\
Positive & $0.18 \pm 0.009$ & $0.026 \pm 0.004$ & $0.029 \pm 0.012$ \\
$150 \mathrm{mg} / \mathrm{kg}$ & $0.59 \pm 0.024$ & $0.028 \pm 0.004$ & $0.036 \pm 0.007$ \\
$300 \mathrm{mg} / \mathrm{kg}$ & $0.60 \pm 0.020$ & $0.034 \pm 0.007$ & $0.049 \pm 0.026$ \\
$450 \mathrm{mg} / \mathrm{kg}$ & $0.80 \pm 0.014$ & $0.054 \pm 0.026$ & $0.067 \pm 0.012$ \\
\hline
\end{tabular}

\section{Sexual behaviour study}

The mounting frequency of all groups was shown in Table 3. Based on the figure shown, treatment groups illustrated a significant increase of mounting frequency compared to both negative and positive controls. Based on Table 3, it was seen that the mounting frequency of $450 \mathrm{mg} / \mathrm{kg} \quad G$. procumbens significantly increase (9 \pm 0.61$)$ compared to all groups, with mounting latency starts as early as $4.43 \pm 0.20$ minutes. Negative control showed no number of mounting frequency, meanwhile, positive control displayed a low number of mounting frequency which is at $4 \pm 0.58$, with mounting latency at $13 \pm 0.94$ minutes. Statistical analysis demonstrated no significant difference between treated groups.

Table 3. Table showed libido analysis of each group after 14 days of treatment, based on mounting latency and frequency.

\begin{tabular}{lll}
\hline Group & Mountin g Latency $(\mathbf{m i n})$ & Mounting frequency \\
\hline Normal & $5.71 \pm 0.52$ & $10 \pm 0.37$ \\
Diabetes & $14.80 \pm 0.10$ & $0 \pm 0.18$ \\
Metformin & $13.00 \pm 0.94$ & $4 \pm 0.58$ \\
$150 \mathrm{mg} / \mathrm{kg}$ & $10.57 \pm 0.87$ & $6 \pm 0.81$ \\
$300 \mathrm{mg} / \mathrm{kg}$ & $7.86 \pm 0.55$ & $5 \pm 0.42$ \\
$450 \mathrm{mg} / \mathrm{kg}$ & $4.43 \pm 0.20$ & $9 \pm 0.61$ \\
\hline
\end{tabular}

\section{Implantation sites}

Implantation sites were counted after fertility test was performed. Based on the results, all treated groups 
demonstrated higher number of implantation sites compared to negative $(0 \pm 0.29)$ and positive controls $(3 \pm 0.95)$. The administration of $G$. procumbens showed significant increase in numbers of implantation sites upon copulation with oestrous female rats. Treated group $150 \mathrm{mg} / \mathrm{kg}$ GP resulted $4 \pm 1.77$ implantation sites, while $300 \mathrm{mg} / \mathrm{kg}$ GP at $7 \pm 1.9$ and $450 \mathrm{mg} / \mathrm{kg}$ GP with $11 \pm 0.84$ implantation sites. This implies that administration of $G$. procumbens aqueous extract improved the fertility and the functionality of the sperm of diabetic induced male rats. The result for the implantation sites was illustrated in Figure 3.

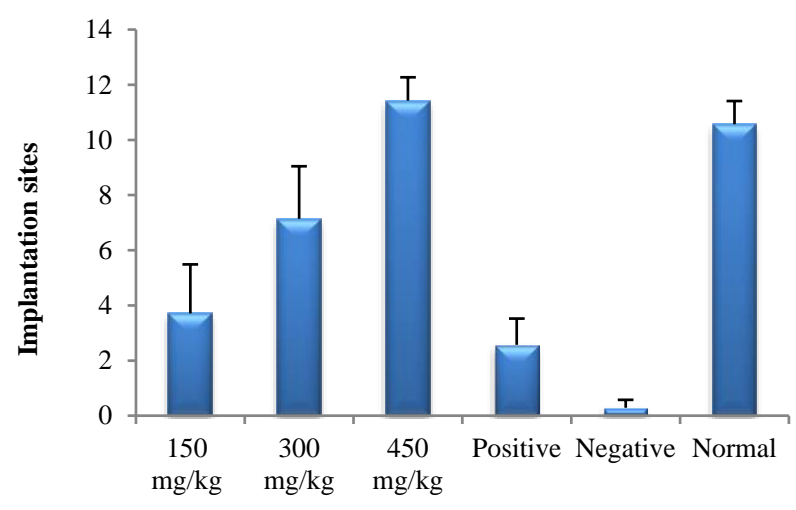

Figure 3. Histogram showed the number of implantation sites of each group after 7 days of treatment.

Diabetes mellitus has caused deleterious effect on male fertility health (Khaki et al., 2014), specifically in low sperm quality (La Vignera, 2012), testicular impairment (Budin et al., 2017) and low libido level (Kamaruzaman \& Noor, 2017). The present study supported these statements, where the sperm quality (sperm count, motility, viability and morphology) were lowered in diabetes compared to the treatment groups. Additionally, the testis histology of the diabetes group showed the same destructive results as reported in Kamaruzaman and Noor (2017) and Noor and Radzuan (2012).

Administration of G. procumbens aqueous extract for seven consecutive days showed a significant reduction of fasting blood glucose level on the treated groups compared to negative and positive controls. Based on the results attained, it revealed that the fasting blood glucose level were reduced in a dose dependent manner. This means that higher dose had better reduction effect, which almost close to the normal blood glucose level. This result is in concur with the previous study reported by Zurina et al., (2010) and Rosidah et al., (2008). The administration of $G$. procumbens extract reduced hyperglycaemia and this conclude that $G$. procumbens extract possessed the anti-hyperglycaemia effect on diabetes subjects.

Long-term diabetes were known to produce high amount of free radicals which resulted the high reactive oxygen species (ROS) (Ozturk et al., 2003). Sperm protein membrane were reported to be consisted of high polyunsaturated fatty acid (PUFA). This PUFA is vulnerable to high amount of ROS (Hales et al., 2005), and it is reported by Pusparanee et al. (2016), that this is one of the factor of significant reduction of sperm quality in diabetes. Oxidative stress was also reported to cause sperm metabolism impairment and the decrease of sperm quality (Amaral et al., 2008). Another study reported that sperm of diabetic male patients were more susceptible to DNA damage due to the oxidative harm (Roessner et al., 2012).

$G$. procumbens were reported to have high antioxidant and polyphenols content, and these were reported to contribute majorly in treatment of hyperglycaemia and fertility, specifically in sperm quality and spermatogenesis ((Hakim et al., 2008; Khaki et al., 2010; Khaki et al., 2014). The presence of antioxidants in $G$. procumbens aqueous extract were reported to be responsible in overcome the overproduction of ROS in diabetes-induced male rats (Rosidah et al., 2008). The present study supported the previous study findings based on the significant increment of sperm quality and the uninterrupted spermatogenesis in the testes histology of all treated groups compared to negative and positive controls.

The administration of G. procumbens aqueous extract also revealed a significant elevation of androgen hormone. The androgen hormone; LH, FSH and testosterone hormone were found to be elevated in treated groups compared to negative and positive controls. This result may be incorporated with the testis histology in this study, where the Leydig and Sertoli cells were normally distributed in the normal control and in the treated groups, where as in the negative and positive control, the Leydig and Sertoli cells were discovered to be damaged. Leydig and Sertoli cells play a major role in spermatogenesis and sperm development (Steger \& Rabe, 1996). The degenerated of these cells could lead to interruption of testosterone hormone secretion. A study reported that high blood glucose level induced change in Leydig cells, and eventually altered the hypothalamic-pituitary-gonadal axis, causing decrease of androgen hormone secretion.

The elevation of androgen hormone, particularly in testosterone hormone lead to an increase of libido of diabetes rats. This results is in parallel to the previous study reported by Kamaruzaman and Noor (2017). The administration of $G$. procumbens aqueous extract for 14 days was significantly increased the libido of diabetes male rats compare to the negative and positive controls. In this study, the results of libido analysis can be seen as fast as after seven days of treatment. The result showed that the higher the dose, the higher the libido of diabetes rats.

Prolonged diabetes or hyperglycaemia revealed that higher ROS produced, and this lead to DNA damage in 
sperm (Roessner et al. 2012). Evidently, administration of G. procumbens extract revealed a high number of implantation sites compared to negative and positive controls. This result showed that the sperm can function as fertilization agent of diabetic male after treatment compared to the diabetic rats. This is also probably due to the antioxidant content of $G$. procumbens extract that able to overcome the overproduction of ROS that is caused by hyperglycaemia.

Metformin, is an established anti-hyperglycaemia drug that is reported to reduce blood glucose level in diabetes patients. However, the usage of metformin in this study showed to be effective in reducing blood glucose level without improving the fertility health of diabetes rats. Furthermore, based on the results attained, the administration of metformin were found to reduce blood glucose level, however, could not reduce the blood glucose level down to normal blood glucose level. In contrast to this, the administration of $G$. procumbens at the highest dose in the study, $450 \mathrm{mg} / \mathrm{kg}$ showed lowered blood glucose level, close to a normal blood glucose level. The consumption of metformin for seven consecutive days also revealed that sperm quality, spermatogenesis, androgen hormones, libido and implantation sites were not improved after seven days of treatment. This finding is in concurrence with previous investigations (Kamaruzaman \& Noor, 2017; Noor \& Radzuan, 2012).

The inclining number of diabetes patients, particularly among the reproductive age has raised concern among researches. The anti-hyperglycaemic drug, metformin has proven to reduce the blood glucose level, however not significantly improved to normal blood glucose level within seven days of consumption. Additionally, the administration of this established drug did not improve the diabetes complication, fertility and libido. Nevertheless, the present study has revealed that the administration of $G$. procumbens aqueous extract showed significant reduction of blood glucose level of diabetes rats, as well as improving fertility and libido health of diabetes rats, and the effect started to be affective as early as seven days consumption using the highest dose at $450 \mathrm{mg} / \mathrm{kg}$. Hence, in conclusion, these lines of evidence revealed that $G$. procumbens aqueous extract possess the potential as anti-hyperglycaemia agent, as well as fertility and libido enhancer.

\section{CONCLUSION}

From that research, we get that libido analysis of seven days treatment showed that GPAE treated groups, significantly improved in $450 \mathrm{mg} / \mathrm{kg}$ dose compared to other groups, with the highest number of mounting frequency and shortest mounting latency. Fertility test revealed a significant increase in number of implantation sites produced in GPAE treated groups compared to positive and negative control groups. In conclusion,
GPAE exhibited a potential beneficial effect as an antidiabetic and also as fertility agent in diabetic-induced male rats.

\section{REFERENCES}

Agmo A. 1997. Protocol male rat sexual behaviour. Brain Research Protocols. 1: 203-209.

Algariri, K., et al,. 2014. Antihyperglycaemic and toxicological evaluations of extract and fractions of Gynura procumbens leaves. Tropical Life Sciences Research, 25(1), 75-93.

Amaral S, Oliveira PJ \& Ramalho-Santos J. 2008. Diabetes and the impairment of reproductive function: possible role of mitochondria and reactive oxygen species. Curr Diabetes Rev. 4(1): 46-54

Biggers, J.D., Whitten, W.K. \& Whittingham, D. 1971. The culture of mouse embryos in vitro. Methods in Mammalian Embryology, J. C. Daniel, Ed., pp. 86-116, Freeman, San Francisco, CA, USA.

Budin, S. B., et al. 2017. Kelulut honey supplementation prevents sperm and testicular oxidative damage in streptozotocininduced diabetic rats. Jurnal Teknologi, 79(3), 89-95. doi:10.11113/jt.v79.9674

Chauhan A \& Agarwal M. 2009. Assessment of the contraceptive efficacy of the aqueous extract of Aegel marmelos Corr. Leaves in the male albino rats. Human Fertility. 12: 10-118.

Hakim, P., Sani, H. A. \& Noor, M. M. 2008. Effects of Gynura procumbens extract and glibenclamide on sperm quality and specific activity of testicular lactate dehydrogenase in streptozotocin-induced diabetic rats. Malaysian Journal of Biochemistry and Molecular Biology, 16, 10-14.

Hakim, P., Sani, H. A. \& Noor, M. M. 2016. Effects of Gynura procumbens on Sperm Quality and Testosterone Level in Streptozotocin-induced Type 1 Diabetic Rats. International Journal of Pharmacognosy and Phytochemical Research, $8(1), 22-30$.

Hales, D. B., Allen, J. A \& Shankara, T. 2005. Mitochondrial Function in Leydig Cell Steroidogenesis. Annals of the New York Academy of Science. 1061: 120-1.

Hassan, Z., et al. 2010. Antidiabetic properties and mechanism of action of Gynura procumbens water extract in streptozotocininduced diabetic rats. Molecules, 15(12), 9008-9023. doi:10.3390/molecules15129008.

Jantan I. 2004. Medicinal plant research in Malaysia: Scientific interests and advances. J Sains Kesihatan Malaysia. 2:27- 46.

Kamaruzaman, K. A. \& MatNoor, M. 2017. Gynura procumbens leaf improves blood glucose level, restores fertility and libido of diabetic-induced male rats. Sains Malaysiana, 46(9), 14711477. doi:10.17576/jsm-2017-4609-16.

Khaki, A., Khaki, A. A. fshi., Hajhosseini, L., Golzar, F. S. adeghpou. \& Ainehchi, N. 2014. The anti-oxidant effects of ginger and cinnamon on spermatogenesis dys-function of diabetes rats. African journal of traditional, complementary, and alternative medicines: AJTCAM / African Networks on Ethnomedicines, 11(4), 1-8. doi:10.4314/ajtcam.v11i4.1.

Khaki, A., Fathiazad, F., Nouri,M., Khaki, A.,Maleki, N.A., Khamnei, H.J., \& Ahmadi, P. 2010. Beneficial effects of quercetin on sperm parameters in streptozotocin-induced diabetic male rats. Phytother Res. 24(9):1285-91.

La Vignera, S., Condorelli, R., Vicari, E., D’Agata, R. \& Calogero, A. E. 2012. Diabetes mellitus and sperm 
parameters. Journal of Andrology, 33(2), 145-153. doi:10.2164/jandrol.111.013193.

Lemmens RHMJ \& Bunyapraphatsara N. 2003. Plant resources of South-East Asia: medicinal and poisonous plants 3. The Netherlands: Backhuys publishers. 12(3): 232.

Noor, M. M. \& Radzuan, N. R. M. 2012. Anti-hyperglycemic effect of Gynura procumbens methanolic extract on fertility and libido of induced diabetic male rats. Sains Malaysiana, 41(12), 1549-1556.

Ozturk, A., et al. 2003. The Effect of Prophylactic Melatonin Administration on Reperfusion Damage in Experimental
Testis Ischemia Reperfusion. Neuroendocrinology Letters. 24: 3-4.

Roessner, C., et al. 2012. Sperm apoptosis signalling in diabetic men. Reprod Biomed Online. 25(3):292-9.

Rosidah, Yam, M., Sadikun, A. \& Asmawi, M. 2008. Antioxidant Potential of Gynura procumbens. Pharmaceutical Biology, 46(9), 616-625. doi:10.1080/13880200802179642.

Steger, R.W. \& Rabe, M.B. 1997. The effect of diabetes mellitus on endocrine and reproductive function. Proc Soc Exp BiolMed. 214: 1-11. 